\title{
NUMERICAL ANALYSIS OF INDIRECT ICE STORAGE SYSTEMS PERFORMANCE
}

\begin{abstract}
C. S. Stampa ${ }^{a}$ |ABSTRACT
A. O. Nieckele

${ }^{a}$ Universidade Federal Fluminense

Department of Industrial Metallurgy

Av. dos Trabalhadores, 420

27255-125, Volta Redonda, RJ, Brazil

cleyton@metal.eeimvr.uff.br

${ }^{\mathrm{b}}$ Pontifícia Universidade Católica do Rio de Janeiro

Department of Mechanical Engineering

Rua Marquês de São Vicente, 225

22453-900, Rio de Janeiro, RJ, Brasil

nieckele@mec.puc-rio.br

A numerical investigation regarding the charging process behavior occurring in a typical indirect ice storage tank is presented. It consists of analyzing the heat transfer and removal of energy, applicable to storage systems, which are chiller-based. In this sense the secondary coolant circulates through a heat exchanger that is submerged in a tank of water and it is used to freeze (charge) the phase-change material (water), which never leaves the storage tank. The thermal exchange process is investigated considering the storage tank in two different positions. In the first one the storage tank is in the vertical position, while for the second, it is horizontally positioned. The storage tank is represented by a channel formed by parallel flat plates, one of which is the heat exchanger. Our task is to provide helpful qualitative results for the heat transfer performance of ice storage tanks. The results are analysed through streamlines and isotherms, for specific instants of time. Further, the heat transfer effectiveness, average heat flux and solid formed at one of the two plates of the channel, are compared for the vertical and horizontal positions of the channel.
\end{abstract}

Keywords: ice storage, numerical, performance

\section{NOMENCLATURE}

$b \quad$ depth of the channel,

$c p$ constant pressure specific heat,

$\Delta h_{\text {lat }}$ latent heat of fusion,

$E_{\text {sens }}$ sensible energy,

$E_{\text {lat }} \quad$ latent energy,

$f_{s} \quad$ formed solid,

g gravitational acceleration vector,

$k$ thermal conductivity,

$m$ mass,

$p \quad$ pressure,

$P \quad$ dimensionless pressure,

$q \quad$ local heat flux,

$\bar{q} \quad$ average heat flux,

rsp constant,

$t$ time,

$T$ temperature,

$\boldsymbol{U} \quad$ liquid velocity vector,

$L \quad$ distance between plates,

$W \quad$ length of the plates,

$x$ horizontal cartesian coordinate,

$y \quad$ vertical cartesian coordinate.

\section{Greek symbols}

$\beta \quad$ exponent of temperature at density,

$\varepsilon \quad$ volume fraction,

$\forall \quad$ volume,

$\mu \quad$ dynamic viscosity,

$\rho$ density,

\section{Subscripts}

$\begin{array}{ll}c & \text { cold wall, } \\ \text { in } & \text { initial, } \\ \ell & \text { liquid, } \\ \text { ref } & \text { reference, } \\ s & \text { solid, }\end{array}$

$m \quad$ melting,

$\max$ maximum.

\section{INTRODUCTION}

Water has been usually adopted as the phasechange material (PCM) in typical fusion latent heat storage systems. Thermal energy storage (TES) for space cooling is an option to reduce electric costs by shifting chilling processes to off-peak times. Due to the high cost of electric on-peak demand and energy charges, TES devices are very popular, since TES can cool the PCM for later use. Thus, heat is removed from the PCM during off-peak times and then passed through a heat exchanger to remove heat from a building in place of chiller operation. One of the main problems concerning the performance of these equipments is that ice storage systems are not steady state devices. Furthermore, besides the parameters that affect any heat exchanger, the critical physical dimensions for phase change thermal storage devices vary as storage material is frozen or melted. High rates of discharge and/or lower temperatures are available early in the melt cycle when the ice surface is close to the heat exchanger, with these capabilities diminishing as the ice surface recedes from the heat exchanger. The main goal of the researches with respect to these heat storage systems has been the determination of the higher capacity of energy accumulation per unit volume, associated with time response.

During the charging process, a complex flow structure and uncommon patterns of temperature distribution can be observed in the melt, due to the inversion density phenomenon for water around $4^{\circ} \mathrm{C}$ (Lin, 1987). This fact affects significantly the thermal exchanges. In this sense, the shape and the growing velocity of ice layer along a cold surface are functions of the velocity and temperature fields in the liquid region, which depend on the initial and boundary conditions considered. 
Predominantly, most of the works that take into account the density inversion phenomenon have been directed to the rectangular vertical and cylindrical horizontal cavities, all of them filled with cold water (Lin, 1987; Mcfadden et al., 1984, Ho, 1990; Inaba, 1988; Tong, 1994; Vasseur et al., 1983). Studies of performance concerning energy storage systems have been the target of many works (Ismail et al., 2000; 2001, Laouadi, 1999; Stampa, 1996, West, 1999). The latter presented a numerical and experimental study of the partial charging and discharging processes, with icing, in tanks of ice storage. Stampa et al. (2001) have also presented a numerical study of natural convection in vertical annular cavity, considering the density inversion phenomenon of the water, however, without formation of the solid phase. In that study, the influence of the multi-cellular regime in the rate of heat transfer was investigated. Recently, Stampa et al. (2002) analyzed the growth of an ice layer around a vertical tube.

To attain our goal regarding optimization of energy storage systems, the present work aims to get useful information for the growth control of ice in indirect ice storage tanks, which are chiller-based. In these equipments, the secondary coolant circulates through a heat exchanger that is submerged in a tank of water and it is used to freeze (charge) the phase-change material (water), which never leaves the storage tank.

The thermal exchange process was investigated by considering the storage tank as a channel formed by parallel flat plates. One of the container's walls was assumed as thermally insulated, and the other representing the heat exchanger surface, was set at a fixed cold temperature, which induced the freezing process. The influence of the relative position of the storage tank in the solidification process was investigated, by considering the flow field in a vertical and horizontal channel. The conditions established in the present study, correspond to a full charging process within the channel. Once the multicellular regime and geometry affect drastically the thermal exchanges, the heat transfer performance of such devices was investigated through the following parameters: heat transfer effectiveness, average heat flux and amount of solid formed. The results for the vertical and horizontal positions of the channel were compared.

\section{MATHEMATICAL MODEL}

The physical model to study ice formation is depicted in Fig. 1, which shows the domain of the process in a certain instant of time, during which the phase change takes place. The domain consists of a parallel flat plate's channel, which can assume the horizontal and vertical positions. Initially, all the water is in the liquid phase at a uniform temperature, $\mathrm{T}_{\text {in }}$. Its value is set above the melting temperature of ice $\left(\mathrm{T}_{\mathrm{m}}=0^{\circ} \mathrm{C}\right)$. The boundary conditions are illustrated at Fig. 1. For a time greater than zero, a cold temperature, $T_{c}$, is imposed at one of the plates, whose value is lower than the melting temperature value. Thus, all the stored latent heat within the channel can be extracted.

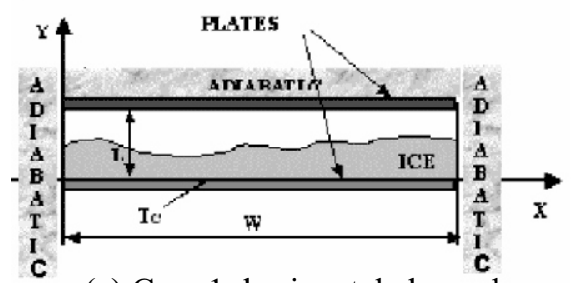

(a) Case 1: horizontal channel

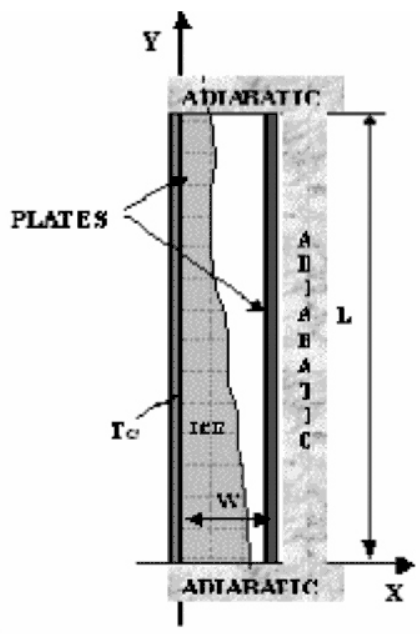

(b) Case 2: vertical channel

Figure 1. Physical domain considered

The problem was modeled as two-dimensional, the PCM was considered as a Newtonian fluid, flowing in the laminar regime. Further, all physical properties were considered constant except the density of the liquid in the buoyancy term. The conservation equations of mass and momentum for the liquid phase, which governs the described process, are:

$$
\begin{gathered}
\nabla \cdot\left(\rho_{\ell} \mathbf{U}\right)=0 \\
\frac{\partial\left(\rho_{\ell} \mathbf{U}\right)}{\partial \mathrm{t}}+\nabla \cdot\left(\rho_{\ell} \mathbf{U} \mathbf{U}\right)=\nabla \cdot\left(\mu_{\ell} \nabla \mathbf{U}\right)-\nabla p+\rho_{\ell} \mathbf{g}
\end{gathered}
$$

where is the specific mass and $\mu$ the absolute viscosity. The subscript $\ell$ corresponds to the liquid properties of PCM. $\mathbf{U}$ is the velocity vector, $p$ is the pressure, $\mathbf{g}$ is the gravitational acceleration vector. The conservation equation of energy is solved in the whole domain, for both solid and liquid phases, being equal to

$$
\begin{gathered}
\frac{\partial\left(\rho_{\ell} c p_{\ell} \varepsilon+\rho_{S} c p_{S}(1-\varepsilon)\right) T}{\partial t} \\
+\nabla \cdot\left(\rho_{\ell} c p_{\ell} \varepsilon \mathbf{U} T\right)= \\
=\nabla \cdot\left(\left(k_{\ell} \varepsilon+k_{S}(1-\varepsilon)\right) \nabla T\right)-\frac{\partial\left(\rho_{\ell} \varepsilon \Delta h_{l a t}\right)}{\partial t}
\end{gathered}
$$

where the thermo-physical properties of the PCM for the liquid ( $\left(\ell\right.$ ) and solid (s) phases, expressed by $\mathrm{k}$ and $\mathrm{c}_{\mathrm{p}}$ are the thermal conductivity and specific heat at constant pressure, respectively. $\mathrm{T}$ is the temperature of the material and $\mathrm{t}$ is the time. $\Delta \mathrm{h}_{\mathrm{lat}}$ is the latent heat of fusion and, $\varepsilon$ is the volume fraction, which is defined as:

$$
\varepsilon=\frac{\forall_{\ell}}{\forall}
$$

where $\forall$ e are $\forall$ the liquid and the total volumes, respectively. 
Initially, as the PCM is in the liquid phase, the volume fraction $\varepsilon$ is equal to one in the whole domain. $\varepsilon$ is set to zero at the regions, where the temperature of the material reaches the value of the fusion temperature of water, $\mathrm{T}_{\mathrm{m}}\left(0^{\circ} \mathrm{C}\right)$. The last term on the right-hand side of Eq. (3) is different from zero only in the regions where the change of phase is occurring. In the third term on the righthand side of Eq. (2), the following density-temperature relationship of water, proposed by Gebhart and Mollendorf (1977), was adopted for the liquid density:

$$
\rho_{\ell}=\rho_{\ell, \max }\left(1-r s p\left|T-T_{\max }\right|^{b}\right)
$$

where $\rho_{6 \text { max }}=999.972 \mathrm{~kg} / \mathrm{m}^{3}, \mathrm{rsp}=9.92710^{-6}\left({ }^{\circ} \mathrm{C}\right), \mathrm{T}_{\max }=$ $4.029{ }^{\circ} \mathrm{C}$ and $\mathrm{b}=1.895$. This relationship takes into account the nature of the inversion-density in the water. The following properties were considered for both phases: $\mu_{c}=1.203 \times 10^{-3} \mathrm{~kg} /(\mathrm{ms}) ; \mathrm{cp}_{\bar{l}}=4200 \mathrm{~J} /(\mathrm{kg} \mathrm{K}) ; \mathrm{cp}_{\mathrm{s}}=2060$ $\mathrm{J} /(\mathrm{kg} \mathrm{K}) ; \mathrm{k}_{\mathrm{c}}=0.602 \mathrm{~W} /(\mathrm{m} \mathrm{K}) ; \mathrm{k}_{\mathrm{s}}=2.3 \mathrm{~W} /(\mathrm{m} \mathrm{K}) ; \Delta \mathrm{h}_{\mathrm{lat}}=$ $333.6 \mathrm{KJ} / \mathrm{kg}$; the reference liquid density was set equal to the solid density, $\rho_{\text {Gref }}=\rho_{\mathrm{s}=} 956.6 \mathrm{~kg} / \mathrm{m}^{3}$.

\section{NUMERICAL METHOD AND ALGORITHM}

To solve the set of coupled equations, Eq. (1) to (3), it was employed the finite volume method (Patankar, 1980). The convective and diffusive fluxes that cross all faces of each control volume were handled by the Power Law scheme. It was considered the fully-implicit time marching technique and the solution method used for the algebraic linear equations was the TDMA line-by-line solver with a block correction method (Settari and Aziz, 1973). To solve the pressure-velocity coupling, the SIMPLE algorithm (Patankar, 1980) was employed.

A fixed and regular grid has been adopted on the physical domain. To define the mesh and time step, a grid test was performed so that variation on the numerical solution were inferior to $1 \%$. A mesh size of $220 \times 160$ nodal points was defined, with a time step of $0.0005 \mathrm{~s}$. Therefore, the chosen values obey a commitment between cost and computable time. Solutions were considered converged at a particular time step if they had residuals of mass and energy less than $10^{6}$ for at least eight consecutive iterations.

\section{RESULTS AND DISCUSSION}

In order to evaluate the heat transfer performance in critical regions inside the channel formed by parallel plates, representing the heat exchanger and the container wall, a charging process (ice making) was analyzed. The numerical simulations were carried out with the channel at horizontal and vertical positions. This effect may be obtained by exchanging the respective numerical values between the dimensions $\mathrm{L}$ and $\mathrm{W}$, as shown in Fig. 1 For these two cases, the charging process was conducted with the PCM being chilled from the same initial temperatures, Tin $=15^{\circ} \mathrm{C}$, and by a cold wall temperature at $T_{C}=-5^{\circ} \mathrm{C}$, imposed to one of the plates at $\mathrm{t}=0 \mathrm{~s}$, as can be seen in Fig. 1. So, the numerical simulations were divided into two cases, which deal with horizontal and vertical surfaces. For the horizontal position the geometric values are $\mathrm{L}=17.6 \times$ $10^{-3} \mathrm{~m}$ and $\mathrm{W}=0.141 \mathrm{~m}$. For the vertical position, they are $\mathrm{L}=0.141 \mathrm{~m}, \mathrm{~W}=17.6 \times 10^{-3} \mathrm{~m}$.
The information concerning the growth of ice within the parallel flat plates channel is obtained through a numerical study of heat transfer and buoyancy-driven flow structure by considering natural convection of water near its density maximum (near $4{ }^{\circ} \mathrm{C}$, at sea level). For all the simulations, streamlines and isotherms were used to show the transient natural convection behavior of the filledwater channel. They were plotted for the times $t$ equal to $180 \mathrm{~s}, 270 \mathrm{~s}, 420 \mathrm{~s}, 620 \mathrm{~s}, 820 \mathrm{~s}, 1220 \mathrm{~s}$ and $2220 \mathrm{~s}$. The same levels were selected in all pictures to allow a judicious comparison. Graphics of average heat flux at the chilled plate, sensible and latent energy removal and formed solid, were also plotted with the variable time in order to investigate the heat transfer problem. The total sensible energy, $E_{S E N S}$, was calculated by:

$$
\begin{gathered}
E_{S E N S}=\int_{\forall_{\ell}} \rho_{\ell} \operatorname{cp}_{\ell}\left(T_{i n}-T\right) d \forall \\
\quad+\int_{\forall_{S}} \rho_{S} c p_{S}\left(\mathrm{~T}_{\mathrm{m}}-T_{C}\right) \mathrm{d} \forall
\end{gathered}
$$

where $c p_{S}$ is the specific of solid and $\rho_{S}$ is the specific mass of solid.

The total latent energy was determined by the following expression:

$$
E_{\text {lat }}=\int_{\forall_{\ell}, 0^{\circ} \mathrm{C}} \rho_{\ell} \Delta \mathrm{h}_{\text {lat }} d \forall
$$

where $\forall_{\ell, 0^{\circ} \mathrm{C}} \quad$ represents a control volume, whose temperature has reached $0^{\circ} \mathrm{C}$. The average heat flux on the cold plate can be found through the expression given by:

$$
\bar{q}=\frac{1}{W} \int_{0}^{W} q d x \text { or } \bar{q}=\frac{1}{L} \int_{0}^{L} q d y
$$

where $\mathrm{q}$ is the local heat flux on the cold plate of the channel and for each case is given by:

$$
\left.\left.q=-k_{\ell} \frac{\partial T}{\partial y}\right)_{\mathrm{y}=0} \text { or } q=-k_{\ell} \frac{\partial T}{\partial x}\right)_{\mathrm{x}=0}
$$

The solid formed is obtained by

$$
f_{s}=\rho_{s}\left(\forall_{T}-\forall_{T, \ell}\right)
$$

where $\forall_{T}$ and $\forall_{T, \ell}$ are the total volume and the liquid total volume

$$
\forall_{T, \ell}=\int_{\forall} \varepsilon d \forall
$$

Since the simulations were performed assuming a two-dimensional situation, a unit depth $b$ perpendicular to Fig.(1) was considered.

Figures 2 and 3 show the transient natural convection behaviors for the horizontal and vertical position of the channel, respectively, corresponding to the 
cooling process (charging) with ice formation. Figures 4 and 5 show the physical representative quantities that may be used to describe the heat transfer problem, which are the latent and sensible energy removed, the solid formed and
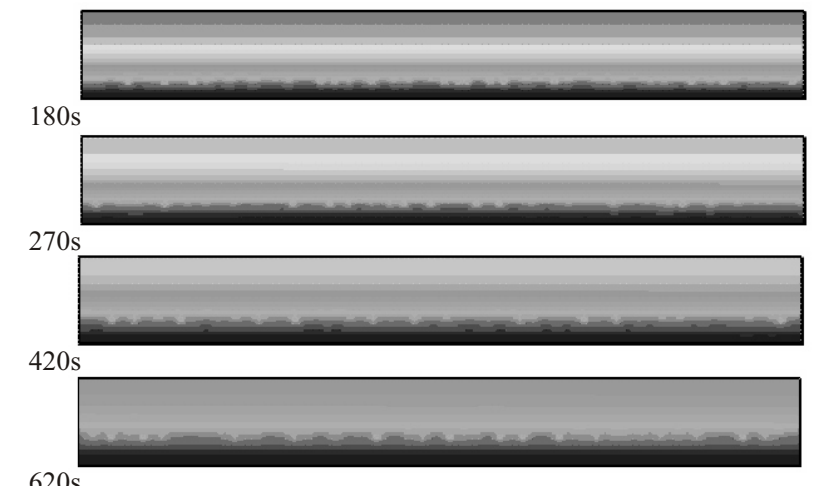
$620 \mathrm{~s}$
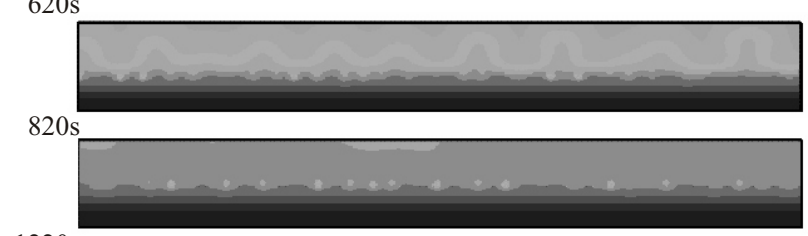

$1220 \mathrm{~s}$

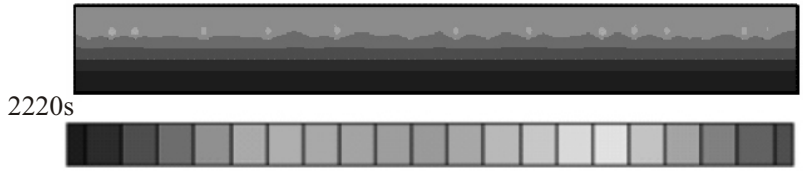

average heat flux at the cold plate. Each of them was plotted including the results for the two relative positions of the channel, which allow us to make comparisons with regard to the details that characterizes thermal differences between horizontal and vertical parallel surfaces.
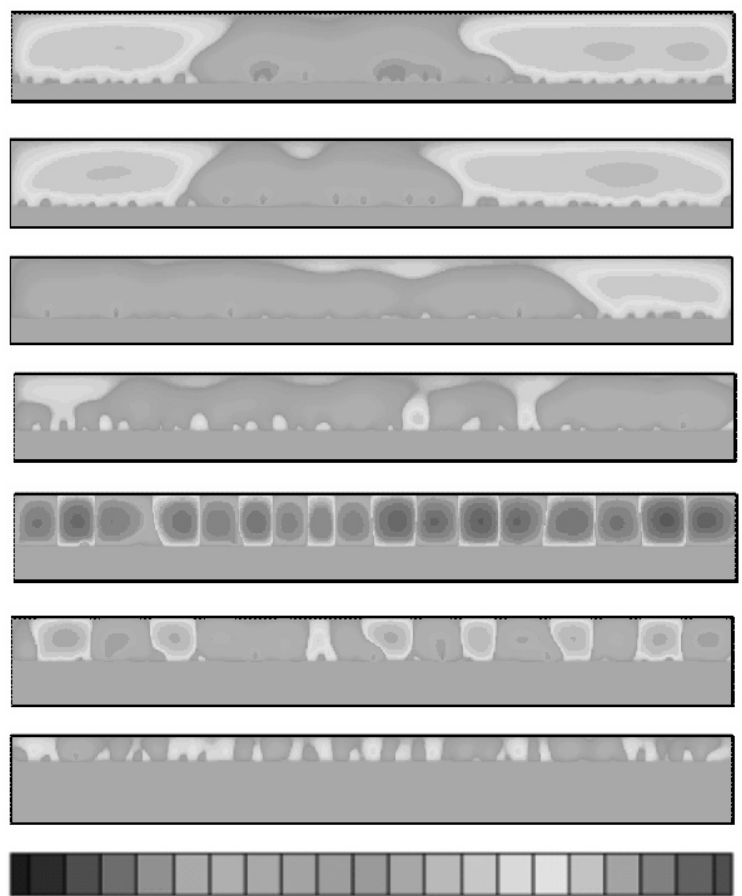

$\begin{array}{lllll}\psi-10^{-2} & -510^{-5} & 0 & 510^{-6} & 10^{-3}\end{array}$

(b) Streamlines

(a) Isotherms

Figure 2- Isotherms and streamlines for horizontal position. From top to bottom:

$\mathrm{t}=180 \mathrm{~s}, \mathrm{t}=270 \mathrm{~s}, \mathrm{t}=420 \mathrm{~s}, \mathrm{t}=620 \mathrm{~s}, \mathrm{t}=820 \mathrm{~s}, \mathrm{t}=1220 \mathrm{~s}$ e $\mathrm{t}=2220 \mathrm{~s}$.

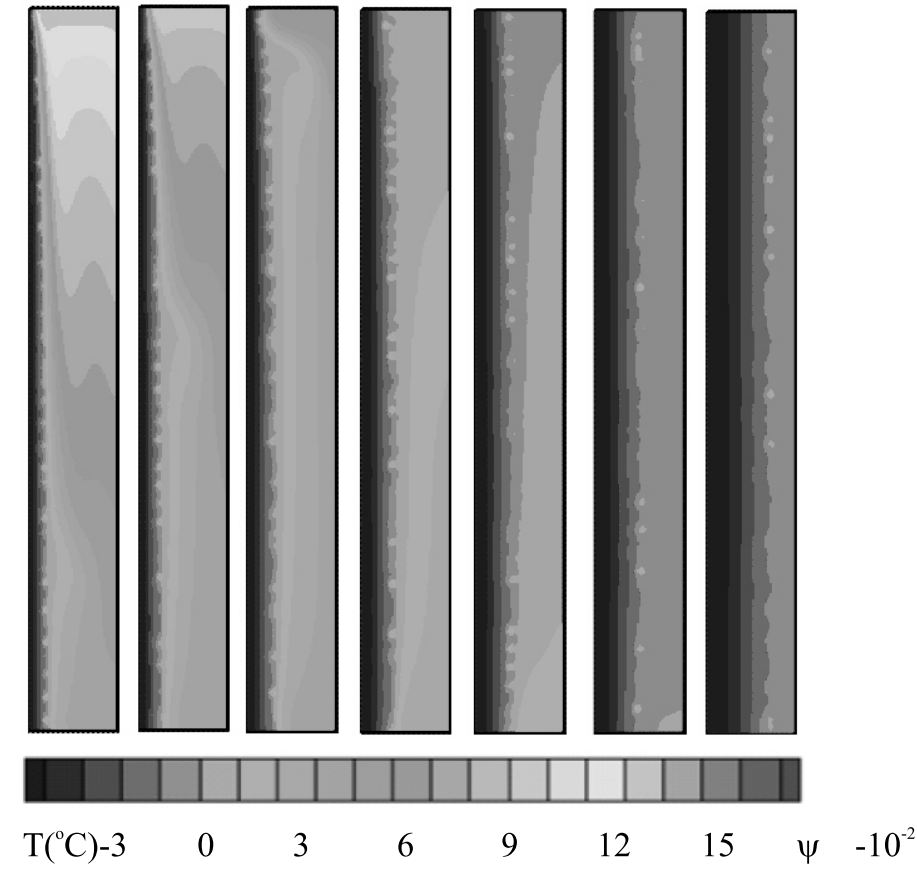

(a) Isotherms
Figure 3- Isothe

$$
\mathrm{t}=180 \mathrm{~s}, \mathrm{t}=270 \mathrm{~s}, \mathrm{t}=420 \mathrm{~s}, \mathrm{t}=620 \mathrm{~s}, \mathrm{t}=820 \mathrm{~s}, \mathrm{t}=1220 \mathrm{~s} \text { e t= } 2220 \mathrm{~s} .
$$


It is known that the multi-cellular regime, which arises due to the inversion density phenomenon of water, affects drastically the thermal exchanges. According to Figs. 2 and 3, one notices that it occurs earlier in the horizontal channel than in the vertical one. In the former channel, it can be observed from $t=180 \mathrm{~s}$ the presence of two large cells, each one situated at the extremes of the channel. They are of similar intensity and size, and rotate in the clockwise sense. Yet, in the central part of the channel there exist a nucleus of smaller cells rotating in the opposite sense. On the other hand, for the same instant of time $(t=180 \mathrm{~s})$, the channel in the vertical position presents a natural convection pattern in the melt such that a hot big counterclockwise cell moves clock wisely a smaller cold one, situated at the bottom of the channel, by means of inertia and friction effects.

By comparing the intensity of all the cells mentioned above, it can be verified that the cells of the channel in the vertical position rotate much faster than that ones for the channel in the horizontal position. This difference in the recirculation velocities can be felt in the temperature distribution over the channels, making the homogenization of this variable faster in the vertical than in the horizontal position of the channel. This fact is clearly observed in Fig. 4 through the graphic for sensible energy removal, where it can be noted the larger amount of energy extracted with the channel in the vertical position. Further, most of the sensible energy is removed from the melt, since there are no significant differences in the formed solid for these two positions, as shown in Fig. 5. It is important to note that the smaller energy extracted from the channel in the horizontal position is also due to the multi-cellular regime, which is very dominant over the time.

As time proceeds, the flow patterns in the remaining melt of the channel in the horizontal and vertical positions tends to be similar. As a consequence, the amount of sensible energy removed will be close for the two positions of the channel for long periods of working. Furthermore, as the PCM in the vertical channel becomes cold first, more latent heat should be extracted from it and more solid should be formed as well, as shown in Figs. 4 and 5. There is practically no difference in the behavior of the heat flux for the two positions of the channel. Thus, one verifies small dependence in the performance of such equipments under charging, concerning horizontal and vertical channels formed by the container and heat exchanger surfaces, despite of the differences pointed out in the present study with regard the heat transfer and natural convection patterns for the two considered positions of the channel.

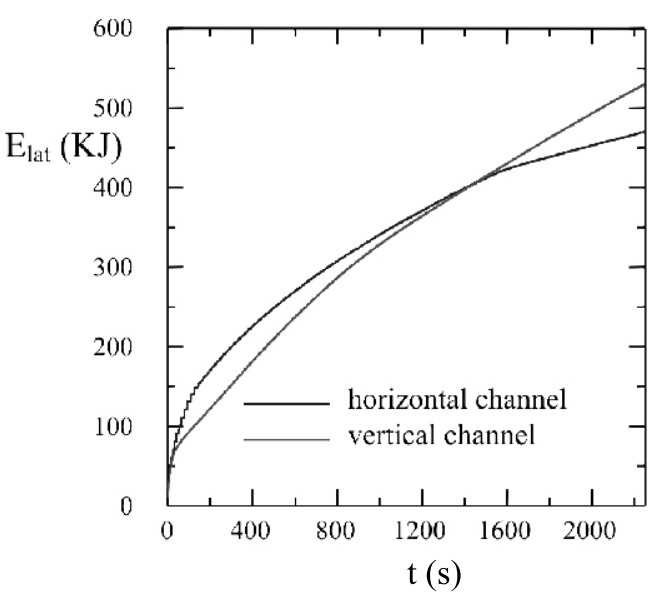

(b) latent energy

Figure 4- Removal of sensible and latent energies.

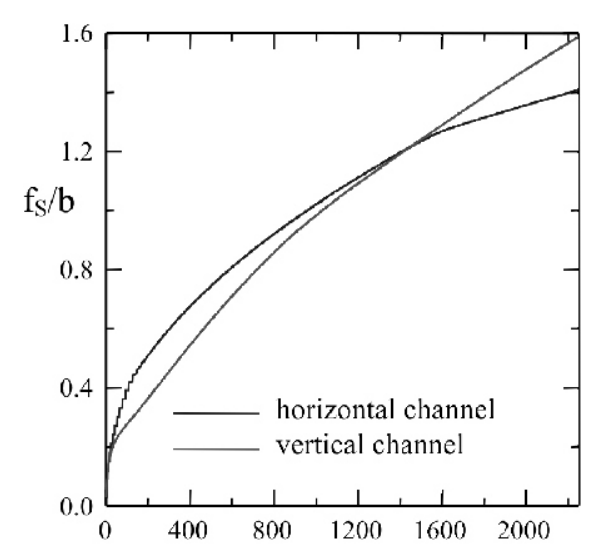

(a) formed solid $(\mathrm{kg} / \mathrm{m})$

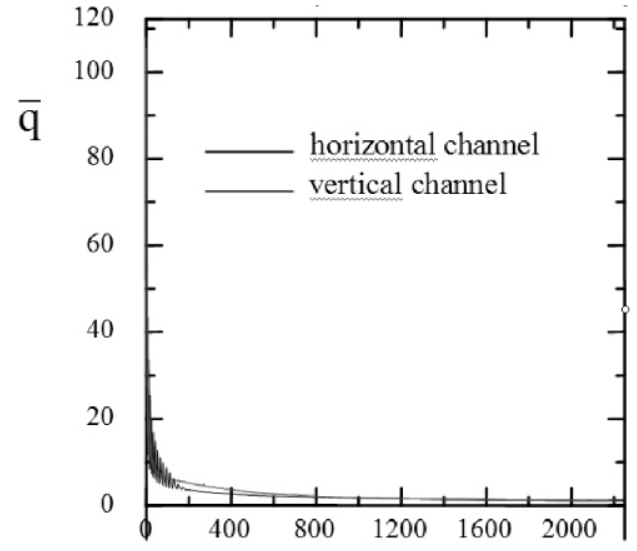

(b) average heat flux $(\mathrm{W} / \mathrm{m})$

Figure 5- Solid formed and average heat flux at the cold plate. 


\section{CONCLUSION}

This work presented a study directed toward the optimization of indirect ice storage systems, which are chiller based. It is part of the continuous efforts, which is been done, aiming an improvement in the performance of ice storage systems. The thermal exchange in critical regions formed between some wall of the heat exchanger and the container wall has been presented. The solution was obtained in a channel formed by parallel flat plates which was considered to simulate such regions, allowing the investigation of the flow and heat transfer in horizontal and vertical regions of the heat exchanger. The effects of density inversion were considered at the present paper, since, according to previous works, the multi-cellular regime, caused by the density inversion phenomenon, affects drastically the heat transfer performance.

An overview of the results show that there is a small dependence in the performance of such equipments under charging, concerning horizontal and vertical channels formed by the container and heat exchanger surfaces, despite of the differences pointed out in the present study with regard the heat transfer and natural convection patterns for the two considered positions of the channel. However, supplementary studies are still necessary to analyze whether the distance between such surfaces may change these results.

\section{ACKNOWLEDGEMTS}

The authors thank CNPq for the support during the development of this work.

\section{REFERENCES}

Gebhart, B., Mollendorf, J. C., 1977, A New Density Relation for Pure And Saline Water, Deep Sea Research, Vol. 24,pp. 831-848.

Ho, C. J., Lin, Y. H., 1990, Natural Convection Heat Transfer of Cold Water Within an Eccentric Horizontal Cylindrical Annulus, Journal of Heat Transfer, Vol. 112, pp. 117-123.

Inaba, H., Fukuda, T., 1988, Natural Convection in an Inclined Square Cavity in Regions Of Density Inversión OfWater, Journal of Fluid Mech., Vol. 110, pp. 894-900.

Ismail, Kamal A. R., Abugderah, Mabruk M., 2000, Performance of a Thermal Storage System of The Vertical Tube Type, Energy Conversion \& Management, Vol. 41, pp.1165-1190.

Ismail, Kamal A. R., Henriquez, J. R., Moura, L. F. M., Ganzarolli, M. M., 2000, Ice Formation Around Isothermal Radial Finned Tubes, Energy Conversion \& Management, Vol. 41, pp.585-605.

Laouadi, A., Lacroix, M., 1999. Thermal Performance of a Latent Heat Energy Storage Ventilated Panel of Electric Load Management, Int. J. of Heat and Mass Transfer, Vol. 42, pp. 275-286.

Lin, D., Nansteel, N. W., 1987, Natural Convection Heat Transfer In A Vertical Annulus Containing Water Near The Density Maximum, Journal of Heat Transfer, Vol. 109, pp. 899-905.

Mcfadden, G. B., Coriell, S. R., Boisvert, R. F. Glicksman, M. E., 1984, Asymmetric Instabilities In Buoyancy-Driven Flow In A Tall Vertical Annulus, Phys. Fluids, Vol. 27, pp. 1359-1361.

Patankar, S. V., 1980, Numerical Heat Transfer and Fluid Flow, Hemisphere Publishing, New York.
Settari, A. \& Aziz, K., 1973, A Generalization Of The Additive Correction Methods For The Iteractive Solution Of Matrix Eq., SIAM J. Of Numerical Analysis, Vol. 10, pp. 506-521.

Stampa, C. S., Braga, S. L., 1996, Estudo da Recuperação do Calor Armazenado em Materiais De Mudança de Fase No Interior de Dutos Cilíndricos, in: VI Encontro Nacional De Ciências Térmicas, Vol. 2, pp. 985 989.

Stampa, C. S., Nieckele, A O., Braga, S. L., 2001, Water Charging And Discharging Processes In A Vertical Annulus Concerning Area-Constrained, Ice-On-Pipe Storage Tanks, in: Proceedings Of The $2^{\text {nd }}$ International Conference On Computational Heat And Mass Transfer, Rio de Janeiro, RJ, Brazil, CD-ROM.

Stampa, C. S., Nieckele, A O., Braga, S. L., 2002, Estudo do Crescimento da Camada de Gelo do Lado Externo de um Tubo Vertical, in: Proceedings IX Encontro Nacional De Ciências Térmicas, Rio De Janeiro, RJ, Brazil, CD-ROM.

Tong, W., Koster, J., 1994, Density Inversion Effect on Transient Natural Convection in a Rectangular Enclosure, International Journal Of Heat And Mass Transfer, Vol. 37, pp. 927-938.

Vasseur, P., Robbilard, L. Chandra Shecar, B., 1983, Natural Convection Heat Transfer Of Water Within A Horizontal Cylindrical Annulus With Density Inversion Effects, Journal Of Heat Transfer, Vol. 105, pp. 117-123.

West, J., Braun, J. E., 1999, Modeling Partial Charging And Discharging Of Area-Constrained Ice Storage Tanks, International HVAC\&R, Vol. 5, No 3, pp. 209-228. 